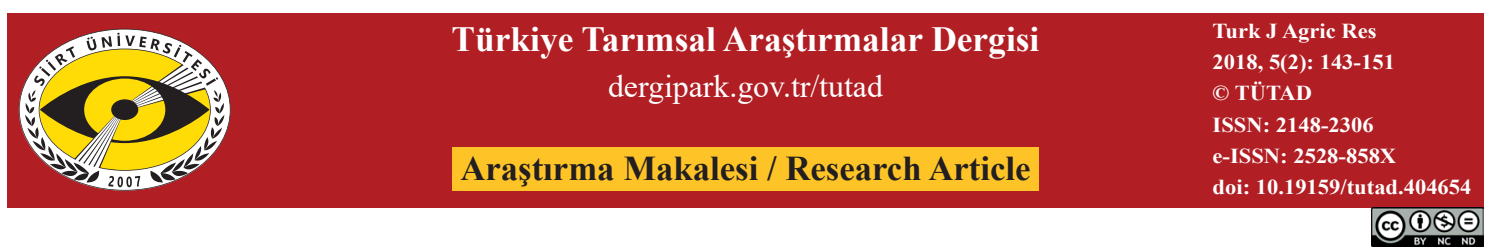

\title{
Kök-Ur Nematodu (Meloidogyne incognita) ve Domates Bitkisinin Gelişimine Bazı Mikrobiyal Gübrelerin Etkisi*
}

\author{
Gökhan AYDINLI ${ }^{1 * *}$, Sevilhan MENNAN ${ }^{2}$ \\ ${ }^{1}$ Ondokuz Mayls Üniversitesi, Bafra Meslek Yüksekokulu, Bitkisel ve Hayvansal Üretim Bölümü, Samsun, TÜRKIYE \\ ${ }^{2}$ Ondokuz Mayıs Üniversitesi, Ziraat Fakültesi, Bitki Koruma Bölümü, Samsun, TÜRKIYE
}

\begin{tabular}{ll}
\hline \multicolumn{1}{c}{ Geliş Tarihi/Received: 12.03 .2018} & Kabul Tarihi/Accepted: 13.06 .2018 \\
\hline ORCID ID (Yazar strasina göre / by author order) & \\
${ }^{*}$ Sorcid.org/0000-0002-3280-0411 (Dorcid.org/0000-0002-4346-8100 \\
\hline
\end{tabular}

Özet: Bu çalışma, bazı ticari mikrobiyal gübrelerin kök-ur nematodu Meloidoyne incognita ve domates gelişimine etkisini değerlendirmek amacıyla yürütülmüştür. Bu amaçla saksı denemeleri kurulan çalışmada; Nematofix ${ }^{\circledR}(N)$, Rootsafer ${ }^{\circledR}(R)$, Phosfert ${ }^{\circledR}(P)$ ve Endoryza ${ }^{\circledR}(E)$ 'dan oluşan mikrobiyal gübreler, tekli ve kombinasyonlar (ikili, üçlü ve dörtlü) şeklinde değerlendirmeye alınmıştır. Nematod verilmeyen bitkilerde, hiçbir uygulama gövde boyunda önemli bir artışa neden olmazken, bazı mikrobiyal gübrelerin bir arada kullanıldığı uygulamalar $(\mathrm{N}+\mathrm{R}+\mathrm{P}, \mathrm{N}+\mathrm{P}+\mathrm{E}, \mathrm{R}+\mathrm{P}+\mathrm{E}$ ve $\mathrm{N}+\mathrm{R}+\mathrm{P}+\mathrm{E}) \mathrm{kontrol}$ grubuna göre önemli artışlar sağlamıştır ( $<<0.05)$. Gövde kuru ağırlığı ve kök yaş ağırlığı bakımından ise sadece mikrobiyal gübrelerin hepsinin bir arada kullanıldığı uygulamada $(\mathrm{N}+\mathrm{R}+\mathrm{P}+\mathrm{E})$ kontrole göre pozitif yönde bir farklılık tespit edilmiştir $(\mathrm{p}<0.05)$. Bu uygulama grubu, nematod verilen bitkilerde, kontrole göre gelişim kriterlerinin tamamında istatistiksel olarak önemli artışın görüldüğü tek uygulamadır. Mikrobiyal gübre uygulamalarında, en düşük ur skalası (5.6), sadece P uygulanan bitkilerde tespit edilirken, sadece $\mathrm{N}$ uygulanan bitkilerde ise en düșük yumurta sayısı ve üreme indeksi belirlenmiștir. Domates bitkisinde $M$. incognita'nın üremesini kontrole göre yaklaşık \% 54 azaltan Nematofix, bu zararlının sorun olduğu yerlerde diğer mücadele yöntemleri ile birlikte kullanılabilme potansiyeline sahiptir.

Anahtar Kelimeler: Meloidogyne incognita, domates, mikrobiyal gübre, bitki gelişimi

\section{Effect of Some Microbial Fertilizers on Tomato Growth and Root-Knot Nematode (Meloidogyne incognita)}

\begin{abstract}
This study was conducted to evaluate the effects of some commercial microbial fertilizers on root-knot nematode Meloidoyne incognita and tomato growth. For this purpose, pot experiments were carried out in the study; Microbial fertilizers consisting of Nematofix ${ }^{\circledR}(N)$, Rootsafer ${ }^{\circledR}(R)$, Phosfert ${ }^{\circledR}(P)$ and Endoryza ${ }^{\circledR}(E)$ were evaluated as individual and combinations (double, triple and quadruple). While none of the applications caused any increase for stem height in the plants without nematode, some applications used by some combinations $(\mathrm{N}+\mathrm{R}+\mathrm{P}, \mathrm{N}+\mathrm{P}+\mathrm{E}, \mathrm{R}+\mathrm{P}+\mathrm{E}$, and $\mathrm{N}+\mathrm{R}+\mathrm{P}+\mathrm{E})$ of microbial fertilizers caused significant changes compared to control $(\mathrm{p}<0.05)$. Plant stem dry weight and root fresh weight were positively affected compared to control $(\mathrm{p}<0.05)$ only when all microbial fertilizers were used together $(\mathrm{N}+\mathrm{R}+\mathrm{P}+\mathrm{E})$. This is the only application group where a statistically significant increase was observed in all of the plant criteria relative to the control in nematode-inoculated plants. The lowest gall index (5.6) was detected only in P treatment, while $\mathrm{N}$ only treatment had the lowest egg number and the reproductive index. Nematofix, which reduces the reproduction of $M$. incognita by about $54 \%$ compared to the control, has the potential to be used with other control methods where this nematode is a problem.
\end{abstract}

Keywords: Meloidogyne incognita, tomato, microbial fertilizer, plant growth

": Bu çalışma, 04-07 Ekim 2011 tarihleri arasında düzenlenen X. Ulusal Ekoloji ve Çevre Kongresi’nde poster olarak sunulmuş olup, özeti yayınlanmıştır. 


\section{Giriş}

İnsan beslenmesinde önemli bir yere sahip olan domates (Solanum lycopersicum L.), dünyada en fazla yetiştirilen tarım ürünlerindendir. Dünyada domates üretimi 2016 yılı verilerine göre 177 milyon ton civarında olup, Türkiye yaklaşık 12.6 milyon ton üretim hacmi ile Çin, Hindistan ve Amerika Birleşik Devletleri'nden sonra dünyanın dördüncü en büyük domates üreticisidir (Anonymous, 2018). Bitki paraziti nematodlar içerisindeki en önemli grubu oluşturan kök-ur nematodları (Meloidogyne spp.)'nın farklı domates çeşitlerinde meydana getirdiği ürün kaybı \% 25100 arasındadır (Seid ve ark., 2015). Özellikle kısa rotasyon ve nadas süresine sahip olan örtü altı üretim alanlarının, nispeten yüksek toprak sıcaklıklarına sahip olmaları, nematodların ve toprak kökenli hastalıkların önemli zararlar oluşturmasına imkan sağlamaktadır (Lopez-Perez ve ark., 2011). Bu nedenle, bu üretim alanları, sadece bitkiler için değil hastalık ve zararlılar için de uygun çevre şartlarına sahiptir (Aydınlı ve Mennan, 2016).

Kök-ur nematodları ile mücadelede sentetik nematisit kullanımı, hatta topraksız tarım gibi çeşitli mücadele yöntemleri denenmiştir (Seid ve ark., 2015). Kullanılan kimyasalların pahalı olmasının yanı sıra çevre ve insan sağlığına olumsuz etkilerinin bulunması mücadelede yeni arayışlara yol açmıştır. Özellikle toprak fumigantı olarak kullanılan Metil Bromid'in yasaklanmasıyla alternatif olarak dayanıklı çeşitlerin kullanımı ön plana çıkmıştır (Djian-Caporalino ve ark., 2011). Kök-ur nematodunun en yaygın türleri olan Meloidogyne incognita (Kofoid \& White) Chitwood, Meloidogyne javanica (Treub) Chitwood ve Meloidogyne arenaria (Neal) Chitwood karşı dayanıklılık sağlayan Mi genine sahip domates çeşitlerinin kullanımı hızlı bir şekilde artmıştır (Lopez-Perez ve ark., 2006). Fakat çeşitlerin her zaman arzu edilen tarımsal özelliklere sahip olmaması, $28{ }^{\circ} \mathrm{C}$ 'nin üzerinde etkinliğini kaybetmesi, sadece belli türlere karş1 dayanıklılık sağlaması ve bu türler içerisinde dayanıklılığı kıran popülasyonların ortaya çıkması, mücadelede diğer alternatiflerin üzerinde durulması gerekliliğini doğurmuştur. Özellikle, insan ve çevre sağlığı açısından artan hassasiyetin bir göstergesi olarak ortaya çıkan tarımsal uygulama modellerinden ekolojik tarım ve iyi tarım uygulamalarında, biyolojik organizmaların kullanımı giderek yaygınlaşmaktadır. Çoğunlukla fungus ve bakterilerden oluşan mikrobiyal organizmaların kök-ur nematodları ile mücadelede kimyasallara alternatif olabilecek potansiyele sahip olduğu belirtilmektedir (Burkett-Cadena ve ark.,
2008). Kök-ur nematodları ile aynı yaşam alanını paylaşan bu organizmalardan bazıları, doğrudan nematod üzerinde etkili olarak mücadelede kullanılabilirken, bazıları bitkilerin kök gelișimini teşvik ederek nematoddan kaynaklanan zararı azaltabilmektedir. Purpureocillium lilacinum (sinonim Paecilomyces lilacinus), Pochonia chlamydosporia (sinonim Verticillium chlamydosporium), Trichoderma harzianum, T. virens, T. lignorum gibi fungal organizmalar ile Pasteuria penetrans, Pseudomonas spp., Bacillus spp., gibi bakteriyel organizmalar kök-ur nematodları ile mücadele başarılı sonuçlar vermiştir (Siddiqui ve Mahmood, 1996; Katı ve Mennan, 2006; Sharon ve ark., 2011; Timper, 2014). Bitki gelişimini düzenleyen bakteriler (PGPR) olarak adlandırılan Bacillus, Pseudomonas, Agrobacterium, Azotobacter cinsi bakterilerin nematodlar için toksik etkiye sahip antibiyotikler ve sekonder metabolitler ürettikleri ve bu şekilde nematod popülasyonunu baskıladıkları belirtilmiştir (Siddiqui ve Shaukat, 2003; Terefe ve ark., 2009). Arbüsküler mikoriza (AM) olarak adlandırılan funguslar ise Glomus, Gigaspora ve Acaulospora cinsine ait türlerden oluşmaktadır. Özellikle kök bölgesinde kolonize olan AM funguslarının da toprak kökenli hastalık etmenlerinin ve bitki paraziti nematodların gelişimini azaltıcı etkileri olduğu bilinmektedir (Liu ve ark., 2012).

Hem Türkiye'de hem de dünyada biyolojik organizmaları bünyesinde bulundurulan çeşitli preparatlar farklı tarımsal alanlarda kullanılmaktadır. Bunlardan bir kısmı biyolojik gübre olarak bir kısmı ise nematisit olarak ruhsatlandırılmıştır. Biyolojik gübre olarak satılmakta olan ve kök-ur nematodlarının doğal düşmanlarını içeren bazı preparatların, nematod popülasyonu üzerine etkileri ise bilinmemektedir. Bu çalıșmada, ticari firmadan temin edilen 4 farklı mikrobiyal gübrenin tek tek veya bir arada kullanıldığında, domates bitkisinin gelişimine ve M. incognita üzerine olan etkisi saks1 denemeleriyle araştırılmıştır.

\section{Materyal ve Yöntem}

Araştırmanın ana materyalini; Falcon domates çeşidi (May Tohumculuk, Türkiye), kök-ur nematodu ( $M$. incognita) ve ticari preparatlar Nematofix ${ }^{\circledR}, \quad$ Rootsafer $\AA$, Phosfert ${ }^{\circledR} \quad$ ve Endoryza ${ }^{\circledR}$ (Bioglobal A.Ş, Antalya, Türkiye) oluşturmaktadır.

\subsection{Test bitkilerin yetiştirilmesi}

Test bitkisi olarak M. incognita'ya hassas Falcon domates çeşidi kullanılmıştır. Domates tohumları, torf içeren viyollere ekildikten sonra 
$25 \pm 2 \quad{ }^{\circ} \mathrm{C}$ sicaklıktaki serada 3-4 yapraklı fide haline gelene kadar yetiştirilmiştir.

\subsection{Nematod inokulumu}

Çalışmada kullanılan kök-ur nematodu popülasyonuna ait yumurta inokulumu, domates bitkisinde seri kültüre alınmış olan saf M. incognita popülasyonundan elde edilmiştir. Bu amaçla yeteri kadar domates bitkisi sökülerek, kökleri iyice yıkandıktan sonra 1-2 cm'lik parçalar halinde kesilmiştir. Kesilen kök parçaları, $200 \mathrm{ml}$ hacminde \% 10 'luk çamaşır suyu solüsyonu $(\% 0.5 \mathrm{NaOCl})$ bulunan cam erlenmayer içerisinde 3 dakika kuvvetlice çalkalanmıştır (Hussey ve Barker, 1973). Daha sonra köklerin bulunduğu bu solüsyon 200 ve 500 mesh'lik eleklerden geçirilerek, 500 meshlik elek üzerinde kalan yumurtalar, piset yardımıyla cam beher içerisine toplanmıştır. $\mathrm{Bu}$ şekilde elde edilen yumurta inokulumu, mikroskop altında sayıldıktan sonra denemenin tamamında kullanılmıştır.

\subsection{Mikrobiyal gübrelerin hazırlanması}

Mikrobiyal gübreler ve içerdikleri mikroorganizmalar Tablo 1'de verilmiştir. Çalışmalarda kullanılan mikrobiyal gübrelerin dozu, firma tarafindan gönderilen tavsiye dozları dikkate alınarak hesaplanmıştır. Buna göre, Phosfer için 1 litre suya $15 \mathrm{ml}$, diğerleri için ise 1 litre suya 5 gram olacak şekilde ayarlanmıştır.
Nematofix ve Rootsafer yanında verilen aktivitörlerle birlikte 1:1 oranında karıştırılarak kullanılmıştır. Denemede kullanılan mikrobiyal gübrelerin nematoda etkisini sentetik preparatlarla kıyaslamak amaciyla etkili maddesi Oxamly $\left(240 \mathrm{~g} \mathrm{~L}^{-1}\right)$ olan ruhsatl bir nematisit (Nematade240®) kullanılmıştır.

\subsection{Denemenin kurulması}

Nematofix (N), Rootsafer (R), Phosfert (P), Endoryza (E) tek, ikili $(\mathrm{N}+\mathrm{R}, \mathrm{N}+\mathrm{P}, \mathrm{N}+\mathrm{E}, \mathrm{R}+\mathrm{P}$, $\mathrm{R}+\mathrm{E}, \quad \mathrm{P}+\mathrm{E})$, üçlü $(\mathrm{N}+\mathrm{R}+\mathrm{P}, \mathrm{N}+\mathrm{R}+\mathrm{E}, \quad \mathrm{N}+\mathrm{P}+\mathrm{E}$, $\mathrm{R}+\mathrm{P}+\mathrm{E})$ ve dörtlü $(\mathrm{N}+\mathrm{R}+\mathrm{P}+\mathrm{E})$ olarak hazırlanan kombinasyonları şeklinde uygulanmıştır. Denemede kullanılan steril kumlu toprak kuru ağırlığının yaklaşık \% 5'i kadar su ile nemlendirildikten sonra 250 ml'lik saksılara yerleştirilmiştir. Dikime hazır olan fide kökleri saksılara yerleştirildikten sonra kök bölgesine bitki başına $5 \mathrm{ml}$ olacak şekilde uygulamalar yapılmış ve köklerin üzeri hemen toprak ile kapatılmıştır. Her uygulamaya ait bitkiler 2 gruba ayrılarak, bir gruba nematod inokulasyonu yapılırken, diğer gruba ise nematod bulaştırılmamıştır. Nematod inokulasyonları, uygulamadan hemen sonra kök bölgesine açılan deliklere, bitki başına $1 \mathrm{ml} \mathrm{su}$ içerisinde 1000 yumurta olacak şekilde yapılmıştır. Sadece nematisit (Nematade 240) uygulamas1, nematod inokulasyonundan hemen sonra bitki başına $5 \mathrm{ml}$ olacak şekilde sulama suyu şeklinde

Tablo 1. Denemede kullanılan mikrobiyal gübreler ve içerdikleri mikroorganizmalar

\begin{tabular}{llll}
\hline \multicolumn{1}{c}{ Endoryza ${ }^{\circledR}$} & \multicolumn{1}{c}{ Nematofix ${ }^{\circledR}$} & \multicolumn{1}{c}{ Rootsafer ${ }^{\circledR}$} & Phosfert ${ }^{\circledR}$ \\
\hline Glomus intraradices & Arthrobotrys conoides & Trichoderma lignorum & Azotobacter chroococum \\
Glomus mosseae & Arthrobotrys oligospora & Trichoderma harzianum & Azotobacter vinelandii \\
Glomus aggregatum & Paecilomyces lilacinus & Trichoderma virens & Bacillus polymyxa \\
Glomus clarum & Paecilomyces fumosoroseus & & \\
Glomus monosporus & Verticillium chlamydosporium & & \\
Glomus deserticola & & & \\
Glomus brasilianum & & & \\
Glomus etunicatum & & & \\
Gigaspora margarita & & & \\
\hline
\end{tabular}

verilmiştir. Çalıșma, 5 tekerrürlü olarak (17 uygulama X 5 tekerrür X 2=170 saks1) tesadüf parselleri deneme desenine göre $25 \pm 2{ }^{\circ} \mathrm{C}$ 'deki serada yürütülmüştür.

\subsection{Sonuçların değerlendirilmesi ve istatiksel analizi}

Nematod inokulasyonundan 60 gün sonra bitkiler hasat edilerek bitki gelişimine uygulamaların etkisini değerlendirmek için bitki boyu, bitki gövde yaş ve kuru ağırlığı, kök yaş ağırlığı belirlenmiştir. Köklerdeki urlanma oranı ise 0-10 skalasına göre değerlendirilmiştir (Bridge ve Page, 1980). Nematodun üremesi ile ilgili değerleri belirlemek amacıyla, her bir uygulamaya ait bitki köklerinden yumurtalar, denemenin kurulum aşamasında açıklandığı şekilde elde edilerek mikroskop altında sayılmıştır. Bitki kökünden elde edilen toplam yumurta sayısının (Pf), başlangıçta verilen yumurta sayısına $(\mathrm{Pi}=1000$ yumurta/bitki) oranlanması ile elde edilen üreme indeksine $(\mathrm{R}=\mathrm{Pf} / \mathrm{Pi})$ ait değerler tespit edilmiştir.

İstatistiksel analizler SPSS 13.0 paket programı kullanılarak yapılmıştır. Verilere varyans analizi ANOVA ve Tukey çoklu karşılaştırma testi uygulanmıştır. Mikrobiyal gübrelerin domates bitkisinin gelişimine etkisi (gövde boyu, kök ağırlığı, gövde yaş ve kuru ağırlığı) nematod verilen ve verilmeyen uygulamalar için ayrı ayrı 
analiz edilmiştir. Ayrıca her bir bitki gelişim kriterinin, nematodun varlığındaki değişimi $\mathrm{t}$ testine göre değerlendirilmiştir. Nematod ile bulaşık bitkilerdeki ur skalası, gram kökteki yumurta sayısı ve üreme indeksi değerlerine analiz edilmeden önce $\log _{10}(x+1)$ transformasyonu uygulanmıştır.

\section{Bulgular}

\subsection{Mikrobiyal gübrelerin bitki gelişimine etkileri}

Nematod ile bulaştırılmayan bitkilerde, mikrobiyal gübrelerin domatesin gelişimine etkisi ele alındığında, hiçbir uygulamanın istatistiksel olarak bitki boyunda önemli değişikliğe neden olmadığ tespit edilmiştir ( $\mathrm{p} \geq 0.05$ ) (Tablo 2). Buna karşın aynı bitkilerde, gövde yaş ağırlığ 1 bakımından bazı uygulamalar $(\mathrm{N}+\mathrm{R}+\mathrm{P}, \mathrm{N}+\mathrm{P}+\mathrm{E}$, $\mathrm{R}+\mathrm{P}+\mathrm{E}$ ve $\mathrm{N}+\mathrm{R}+\mathrm{P}+\mathrm{E})$ kontrol grubuna göre önemli artışlar sağlamıştır $(p<0.05)$. Gövde kuru ağırlığı ve kök yaş ağırlığı bakımından ise sadece bütün mikrobiyal gübrelerin bir arada kullanıldığ uygulamada $(\mathrm{N}+\mathrm{R}+\mathrm{P}+\mathrm{E})$ kontrole göre önemli seviyede artış tespit edilmiştir $(\mathrm{p}<0.05)$. Ayrıca, bu uygulama grubu, nematod verilen bitkilerde, kontrole göre değerlendirmeye alınan gelişim kriterlerinin tamamında istatistiksel olarak önemli artışın görüldüğ̈̈ tek uygulamadır.

Her bir uygulamanın nematod verilen ve verilmeyen bitkilerdeki gelişimi $\mathrm{t}$ testine göre kıyaslandığında, ele alınan kriterlerden gövde boyu ve kök yaş ağırlığındaki değişim önemsiz olarak tespit edilirken $(\mathrm{p} \geq 0.05)$, gövde yaş ağırlığındaki

Tablo 2. Meloidogyne incognita ile bulaştırılan (1000 yumurta/bitki) ve bulaştırılmayan domates bitkilerinin gelişimine mikrobiyal gübrelerin etkisi ${ }^{1}$

\begin{tabular}{|c|c|c|c|c|c|}
\hline \multicolumn{2}{|c|}{ Uygulama } & $\begin{array}{l}\text { Gövde boyu } \\
\quad(\mathrm{cm})\end{array}$ & $\begin{array}{l}\text { Gövde yaş } \\
\text { ağırlığ1 } \\
\text { (g) }\end{array}$ & $\begin{array}{l}\text { Gövde kuru } \\
\text { ağırlığı } \\
\text { (g) }\end{array}$ & $\begin{array}{l}\text { Kök yaş } \\
\text { ağırlığ1 } \\
\text { (g) }\end{array}$ \\
\hline \multirow{17}{*}{ 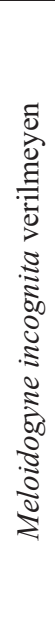 } & Kontrol & $21.00 \mathrm{a}$ & $8.68 \mathrm{def}$ & $1.67 \mathrm{bc}^{*}$ & $3.28 \mathrm{~b}$ \\
\hline & Nematofix & $23.00 \mathrm{a}$ & $9.36 \mathrm{cdef}$ & $1.73 \mathrm{abc}$ & $3.47 \mathrm{~b}$ \\
\hline & Rootsafer & $21.30 \mathrm{a}$ & $9.16 \mathrm{cdef}$ & $1.68 \mathrm{bc}$ & $3.73 \mathrm{ab}$ \\
\hline & Phosfert & $22.30 \mathrm{a}$ & $8.08 \mathrm{f}$ & $1.63 \mathrm{bc}^{*}$ & $3.22 \mathrm{~b}$ \\
\hline & Endoryza & $20.30 \mathrm{a}$ & 8.52 def & $1.64 \mathrm{bc}^{*}$ & $3.65 \mathrm{ab}$ \\
\hline & Nematofix + Rootsafer & $22.20 \mathrm{a}$ & $9.14 \mathrm{cdef}$ & $1.72 \mathrm{bc}$ & $3.85 \mathrm{ab}$ \\
\hline & Nematofix+Phosfert & $21.30 \mathrm{a}$ & 8.42 ef & $1.61 \mathrm{bc}^{*}$ & $3.23 \mathrm{~b}$ \\
\hline & Nematofix + Endoryza & $24.00 \mathrm{a}$ & $9.10 \mathrm{cdef}$ & $1.64 \mathrm{bc}$ & $3.97 \mathrm{ab}$ \\
\hline & Rootsafer+Phosfert & $20.30 \mathrm{a}$ & 8.34 ed & $1.46 \mathrm{c}$ & $3.40 \mathrm{~b}$ \\
\hline & Rootsafer+Endoryza & $21.20 \mathrm{a}$ & $9.26 \mathrm{cdef}$ & $1.56 \mathrm{c}$ & $3.11 \mathrm{~b}$ \\
\hline & Phosfert+Endoryza & $22.50 \mathrm{a}$ & 9.76 bcde & $1.72 \mathrm{bc}^{*}$ & $3.61 \mathrm{~b}$ \\
\hline & Nematofix + Rootsafer + Phosfert & $22.80 \mathrm{a}$ & $10.54 \mathrm{abc}^{*}$ & $1.70 \mathrm{bc}^{*}$ & $3.90 \mathrm{ab}$ \\
\hline & Nematofix+Rootsafer+Endoryza & $24.20 \mathrm{a}$ & 9.46 bcde & $1.61 \mathrm{bc}$ & $3.79 \mathrm{ab}$ \\
\hline & Nematofix + Phosfert+Endoryza & $23.10 \mathrm{a}$ & $10.20 \mathrm{bc}$ & $1.73 \mathrm{abc}$ & $3.66 \mathrm{ab}$ \\
\hline & Rootsafer+Phosfert+Endoryza & $23.80 \mathrm{a}$ & $10.84 \mathrm{ab}$ & $1.90 \mathrm{ab}$ & $4.02 \mathrm{ab}$ \\
\hline & Nematofix + Rootsafer+Phosfert+Endoryza & $24.20 \mathrm{a}$ & $11.70 \mathrm{a}$ & $2.04 \mathrm{a}$ & $4.57 \mathrm{a}$ \\
\hline & Nematade 240 (Nematisit) & $23.10 \mathrm{a}$ & $10.00 \mathrm{bcd}$ & $1.71 \mathrm{bc}$ & $3.78 \mathrm{ab}$ \\
\hline \multirow{17}{*}{ 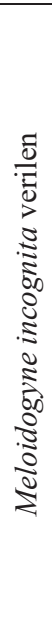 } & Kontrol & $22.10 \mathrm{~b}$ & $8.14 \mathrm{bcd}$ & $1.36 \mathrm{bcd}$ & $3.80 \mathrm{~b}$ \\
\hline & Nematofix & $22.60 \mathrm{ab}$ & $8.34 \mathrm{bcd}$ & $1.49 \mathrm{bcd}$ & $3.56 \mathrm{~b}$ \\
\hline & Rootsafer & $23.70 \mathrm{ab}$ & $9.34 \mathrm{bc}$ & $1.71 \mathrm{abc}$ & $3.61 \mathrm{~b}$ \\
\hline & Phosfert & $21.50 \mathrm{~b}$ & $7.14 \mathrm{~cd}$ & $1.25 \mathrm{~cd}$ & $3.16 \mathrm{~b}$ \\
\hline & Endoryza & $22.20 \mathrm{~b}$ & $7.78 \mathrm{bcd}$ & $1.39 \mathrm{bcd}$ & $3.31 \mathrm{~b}$ \\
\hline & Nematofix + Rootsafer & $21.20 \mathrm{~b}$ & $8.28 \mathrm{bcd}$ & $1.57 \mathrm{abcd}$ & $3.52 \mathrm{~b}$ \\
\hline & Nematofix+Phosfert & $21.00 \mathrm{~b}$ & $6.50 \mathrm{~d}$ & $1.17 \mathrm{~d}$ & $3.05 \mathrm{~b}$ \\
\hline & Nematofix + Endoryza & $22.80 \mathrm{ab}$ & $8.42 \mathrm{bcd}$ & $1.46 \mathrm{bcd}$ & $3.82 \mathrm{ab}$ \\
\hline & Rootsafer+Phosfert & $22.30 \mathrm{~b}$ & $8.28 \mathrm{bcd}$ & $1.35 \mathrm{bcd}$ & $3.14 \mathrm{~b}$ \\
\hline & Rootsafer+Endoryza & $23.80 \mathrm{ab}$ & $9.12 \mathrm{bc}$ & $1.49 \mathrm{bcd}$ & $3.18 \mathrm{~b}$ \\
\hline & Phosfert+Endoryza & $22.80 \mathrm{ab}$ & $8.86 \mathrm{bcd}$ & $1.37 \mathrm{bcd}$ & $3.72 \mathrm{ab}$ \\
\hline & Nematofix+Rootsafer+Phosfert & $23.40 \mathrm{ab}$ & $8.98 \mathrm{bcd}$ & $1.35 \mathrm{bcd}$ & $3.52 \mathrm{~b}$ \\
\hline & Nematofix + Rootsafer+Endoryza & $23.10 \mathrm{ab}$ & $9.18 \mathrm{bc}$ & $1.54 \mathrm{abcd}$ & $4.05 \mathrm{ab}$ \\
\hline & Nematofix + Phosfert+Endoryza & $23.70 \mathrm{ab}$ & $9.74 \mathrm{~b}$ & $1.62 \mathrm{abcd}$ & $4.14 \mathrm{ab}$ \\
\hline & Rootsafer+Phosfert+Endoryza & $23.10 \mathrm{ab}$ & $10.18 \mathrm{ab}$ & $1.80 \mathrm{ab}$ & $3.91 \mathrm{ab}$ \\
\hline & Nematofix + Rootsafer + Phosfert + Endoryza & $26.50 \mathrm{a}$ & $12.54 \mathrm{a}$ & $1.99 \mathrm{a}$ & $4.94 \mathrm{a}$ \\
\hline & Nematade 240 (Nematisit) & $21.00 \mathrm{~b}$ & $9.18 \mathrm{bc}$ & $1.53 \mathrm{abcd}$ & $3.87 \mathrm{ab}$ \\
\hline
\end{tabular}

${ }^{1}$ Uygulamalara ait veriler nematod verilen ve verilmeyen bitkilerde ayrı ayrı analiz edilmiş olup Tukey HSD testine göre sütün içerisinde aynı harflere sahip değerler $\mathrm{p} \leq 0.05$ göre istatistiki olarak farksızdır, ${ }^{*} \mathrm{t}$ testine göre aynı uygulamanın nematod verilen ve verilmeyen bitkilerdeki değerleri $\mathrm{p} \leq 0.05$ göre istatiksel olarak farklıdır 
değişim ise sadece $\mathrm{N}+\mathrm{R}+\mathrm{P}$ kombinasyonunun bir arada uygulandığı bitkilerde önemli derecede fark tespit edilmiştir (Tablo 2). Herhangi bir mikrobiyal gübrenin uygulanmadığ1 kontrol grubunda, nematodun varlığı ele alınan bitki gelişim kriterlerinden sadece gövde kuru ağırlığında istatiksel olarak değişime (azalışa) neden olmuştur. Benzer şeklide, mikrobiyal gübrelerin tek tek kullanıldığ $\mathrm{P}$ ve E ile ikili ve üçlü kombinasyon şeklinde kullanıldığı N+P, P+E ve $\mathrm{N}+\mathrm{R}+\mathrm{P}$ uygulamalarında gövde kuru ağırlığı, nematod ile bulaşık bitkilerde nematod verilmeyenlere göre önemli derecede azalmıştır. Bunların dışındaki mikrobiyal gübre uygulamalarının ise nematodun neden olduğu azalışı tolere edici etkiye sahip olduğu görülmektedir (Tablo 2).

\subsection{Mikrobiyal gübre uygulamalarının nematoda etkisi}

Kök-ur nematodu ile bulaşık bitkilerde kullanılan mikrobiyal gübre uygulamaları içinde en düșük ur skalası (5.6), sadece $\mathrm{P}$ uygulanan bitkilerde tespit edilmiştir (Tablo 3). $\mathrm{N}+\mathrm{P}+\mathrm{E}$ kombinasyonunun bir arada kullanıldığı bitkilerde ise en yüksek ur skalası belirlenmiş olup, bu değer sadece nematod bulaştırılan bitkilerde (kontrol grubunda) elde edilen ur skalası (7.4) ile aynıdır. Mikrobiyal gübrelerin uygulandığı bitkilerde, nematodun yumurta sayısının ve üreme indeksinin en düşük belirlendiği uygulama ise sadece $\mathrm{N}$ bioprepratının uygulandığı bitkilerde görülmüștür. Aynı zamanda, bu uygulamanın kontrol bitkisine göre nematodun üreme indeksini \% 54 azalttığ tespit edilmiştir (Şekil 1).

Tek başlarına uygulandıklarında köklerdeki urlanma oranında azalışa neden olan $\mathrm{N}$ ve $\mathrm{P}$, birlikte karışım şeklinde kullanıldıklarında etkinliklerinin önemli oranda azaldığı tespit edilmiştir. Mikrobiyal gübrelerin hepsinin bir arada $(\mathrm{N}+\mathrm{R}+\mathrm{P}+\mathrm{E})$ kullanıldığı bitkilerin gelişimi, diğer uygulamalara göre daha iyi olmasina rağmen, bu bitkilerdeki nematod üremesinde çok düşük bir azalışa ( $\%$ 20) neden oldukları belirlenmiştir (Şekil 1).

\section{Tartışma ve Sonuç}

Topraktaki mikroorganizmalar, hem doğal alanlarda hem de tarım alanlarında toprak yapısının oluşumunda, organik maddenin parçalanmasında, toksinlerin uzaklaştırılmasında, karbon, nitrojen, fosfor gibi döngülerin işlemesinde kritik bir fonksiyona sahiptir (Van Elsas ve ark., 2006). Son y1llarda, özellikle PGPR olarak adlandırılan bakterilerin, çeşitli stres faktörlerine karşı bitkinin performansını artırıcı etkiye sahip olduğu ve bunun sonucunda bitkide verimi arttırırken, kimyasal gübre ve pestisit kullanımının da azalmasina imkan vererek, sürdürülebilir tarımsal üretimin yapılmasına katk1 sağladığı bilinmektedir (Hariprasad ve ark., 2014; Cetintas ve ark., 2018). Rhizosfer bakterilerinin, bitkide uyarılmış sistemik dayanıklılık olarak ifade edilen mekanizmayı devreye sokarak, bitki patojenlerinin geniş bir dizisine karşı, konukçu bitki dayanıklılığını artırdığı ve hastalık gelişimini baskılayıcı etkiye sahip olduğu da belirlenmiştir (Van Loon ve ark., 1998). Çalışmada değerlendirmeye alınan mikrobiyal gübrelerden, PGPR bakterileri (A. chroococum, A. vinelandii ve $B$. polymyxa) içeren Phosfert'in tek başına uygulandığ 1 bitkilerde ur skalası en düşük olarak tespit edilmiştir. PGPR gibi AM fungusları da bitki

Tablo 3. Domateste Meloidogyne incognita gelişimine mikrobiyal gübrelerin etkisi”

\begin{tabular}{|c|c|c|c|}
\hline Uygulama $^{\mathrm{a}}$ & Ur skalası $(0-10)^{\mathrm{b}}$ & Yumurta sayısı/g kök & Üreme indeksi ${ }^{\mathrm{c}}$ \\
\hline Kontrol & $7.4 \mathrm{a}$ & $9275.45 \mathrm{abc}$ & $34.20 \mathrm{a}$ \\
\hline Nematofix & $6.4 \mathrm{abc}$ & $5035.53 \mathrm{~d}$ & $18.00 \mathrm{f}$ \\
\hline Rootsafer & $6.8 \mathrm{ab}$ & $8924.56 \mathrm{abc}$ & $31.20 \mathrm{abcd}$ \\
\hline Phosfert & $5.6 \mathrm{c}$ & $7357.21 \mathrm{abcd}$ & $22.20 \mathrm{ef}$ \\
\hline Endoryza & $6.4 \mathrm{abc}$ & $7124.95 \mathrm{abcd}$ & 23.40 def \\
\hline Nematofix + Rootsafer & $6.0 \mathrm{bc}$ & $6902.67 \mathrm{abcd}$ & 24.00 cde \\
\hline Nematofix + Phosfert & $6.4 \mathrm{abc}$ & $10231.18 \mathrm{ab}$ & 29.40 abcde \\
\hline Nematofix + Endoryza & $6.6 \mathrm{abc}$ & $8650.91 \mathrm{abc}$ & $33.00 \mathrm{ab}$ \\
\hline Rootsafer + Phosfert & $6.4 \mathrm{abc}$ & $9004.43 \mathrm{abc}$ & 27.00 abcde \\
\hline Rootsafer+Endoryza & $7.2 \mathrm{ab}$ & $10422.73 \mathrm{a}$ & $33.00 \mathrm{ab}$ \\
\hline Phosfert+Endoryza & $7.2 \mathrm{ab}$ & $9423.35 \mathrm{abc}$ & $34.20 \mathrm{a}$ \\
\hline Nematofix + Rootsafer + Phosfert & $7.0 \mathrm{ab}$ & $7772.96 \mathrm{abcd}$ & 25.80 abcde \\
\hline Nematofix + Rootsafer+Endoryza & $7.0 \mathrm{ab}$ & $6080.94 \mathrm{~cd}$ & 24.00 cde \\
\hline Nematofix + Phosfert + Endoryza & $7.4 \mathrm{a}$ & 7550.94 abcd & $31.20 \mathrm{abc}$ \\
\hline Rootsafer+Phosfert+Endoryza & $6.8 \mathrm{ab}$ & $6470.12 \mathrm{abcd}$ & 25.20 bcde \\
\hline Nematofix + Rootsafer + Phosfert + Endoryza & $7.2 \mathrm{ab}$ & $6235.63 \mathrm{bcd}$ & $30.60 \mathrm{abcd}$ \\
\hline Nematade 240 (Nematisit) & $3.0 \mathrm{~d}$ & $703.51 \mathrm{e}$ & $2.70 \mathrm{~g}$ \\
\hline
\end{tabular}




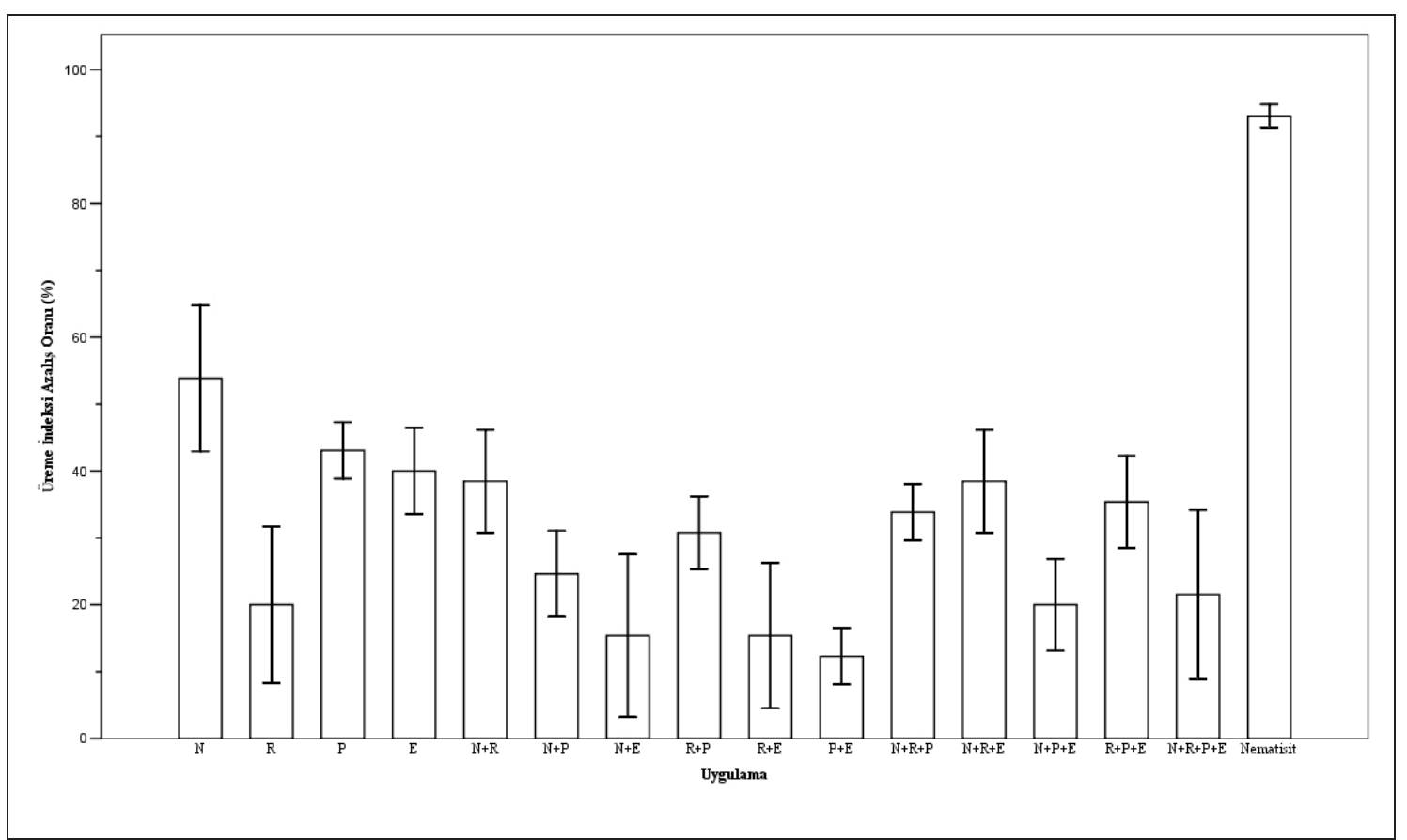

Şekil 1. Nematofix (N), Rootsafer (R), Phosfert (P) ve Endoryza (E) preparatlarının tekli veya kombinasyon şeklinde uygulandığı domates bitkisinin Meloidogyne incognita ile yapay olarak bulaştırılmasından (1000 yumurta/bitki) 60 gün sonra elde edilen üreme indeksi değerlerinin, kontrol bitkilerine göre \% azalış oranı ${ }^{1}$

${ }^{1}$ :Sütunlar ortalamayı $(\mathrm{n}=5)$, sütunda yer alan bar ise standart sapmayı ifade eder

gelişimini artırmakta ve hastalıklara karşı bitkinin toleransını arttırıcı etkiye sahip olabilmektedir (Liu ve ark., 2012). Çalışmada kullanılan mikrobiyal gübrelerden Endoryza, Gigaspora ve Glamus cinsine ait 9 farklı türden oluşan AM funguslarına sahiptir. Arbüsküler mikoriza funguslarının, domatesteki bitki gelişimine ve kök-ur nematodlarına etkisini belirlemek amacıyla yürütülen çalışmalar olduğu gibi (Cooper ve Grandisons, 1986; Shreenivasa ve ark., 2007), bunların aynı amaçla PGPR bakterileri ile bir arada kombinasyon şeklinde kullanıldı̆̆ 1 çalışmalarda bulunmaktadır (Siddiqui ve Akhtar, 2009; Serfoji ve ark., 2010; Liu ve ark., 2012). Arbüsküler mikoriza fungusu G. mosseae ile PGPR bakterisi Bacillus sp.'nin birlikte kullanıldığ1 uygulamalarda, domates bitkisinin gelişiminin, ayrı ayrı kullanıldıklarında elde edilen değerlere göre daha yüksek oranda attırdığ 1 tespit edilmiştir (Liu ve ark., 2012). Bu çalışmada da benzer bir șekilde, Phosfer ve Endoryza'nın bir arada kullanıldığı uygulamalardaki bitki gelişimi, tek tek uygulandıklarında elde edilen değerlerden daha yüksektir. Liu ve ark. (2012), AM fungusları ve PGPR bakterileri birlikte kullanıldıklarında, rhizosfer bölgesinde birbirlerinin kolonizasyonunu arttırarak, bitki gelişimini teşvik etmede sinerjik bir etkiye sahip olduklarını bildirmektedir. Bu çalışmada, böyle bir sinerjik etki en belirgin bir şekilde, dört ticari mikrobiyal gübrenin bir arada kullanıldığı uygulamadan elde edilmiştir.
Çalışmada kullanılan 4 mikrobiyal gübre de tek olarak kullanıldığında, hiç birinin bitki gelişimine önemli etkisi tespit edilmemiştir. Benzer sonuçlar, domates bitkisinde $M$. incognita'nın kontrolünde $B$. subtilis ve $V$. chlamydosporium etkinliğini deneyen Fernandes ve ark. (2014) ile Bacillus licheniformis, B. subtilis ve Trichoderma longibrachiatum içeren bir preparatın (NemOut ${ }^{\mathrm{TM}}$ ) domatesteki $M$. incognita mücadelesinde kullanılabilme potansiyelini araştıran Silva ve ark. (2017) tarafindan da elde edilmiştir.

Kök-ur nematodlarının önemli fungal parazitleri olarak bilinen $P$. chlamydosporium, Arthrobotrys spp. ve $P$. lilacinus türlerini içeren Nematofix, kullanılan uygulamalar içerisinde, nematodu en fazla baskılayanlardır. Bu biyolojik preparatın bünyesinde bulunan $P$. chlamydosporia ve $P$. lilacinum, yumurta paraziti olarak bilinirken, Arthrobotrys spp. ise nematod tuzaklayıc1 funguslardandır (Katı ve Mennan, 2006). Bu preparatın tek başına uygulandığı bitkilerdeki nematod üreme oranı kontrole kıyasla yaklaşık yarı yarıya azalmasına rağmen, denemede kullanılan kimyasal nematisite kıyasla ise etkinliği oldukça düşüktür. Bu fungus türlerinin izolatları arasında nematodu parazitleme yetenekleri bakımından farklılık bulunabilmektedir (Kerry ve ark., 1984; Irving ve Kerry, 1986; Cabanillas ve ark., 1989; Gaspard ve ark., 1990). Gaspard ve ark. (1990), farklı domates tarlalarından izole ettikleri $P$. lilacinum türüne ait 
15 izolat ile $P$. chlamydosporia türene ait 13 izolatın, in vitro koşullarda $M$. incognita yumurtalarını parazitleme yeteneğini araştırdıkları çalışmada, izolatların \% 50'den daha az parazitleme oranı gösterdiğini tespit etmişlerdir. Ayrıca in vitro'daki bu başarı oranı, topraklı uygulamalarda daha düşük olabilmektedir (Kerry ve ark., 1984; Dackman ve Nordbring-Hertz, 1985; Freire ve Bridges, 1985).

Çalışmada kullanılan mikrobiyal gübrelerden Rootsafer'in içeriğinde bulunan Trichoderma türleri, toprak ve kök sisteminde yaygın olarak bulunan serbest formdaki funguslardır (Radwan ve ark., 2012). Trichoderma cinsine ait bazı türler kök bölgesinde kolonize olarak, bitkinin büyümesini, gelişmesini ve verimini artırmakta, abiyotik stress faktörlerine dayanıklılık sağlamaktadır. Ayrıca antigostik etkiler ile bitki patojenlerini ve nematodları kontrol altına alabilmektedir (Sharon ve ark., 2001). Trichoderma türlerinin nematodlara karşı birden fazla etki mekanizması bulunabilmektedir. Bazı türleri doğrudan nematod yumurtasını parazitleyebilirken, bazıları nematoda toksik bileșikler üretebilir ya da ürettikleri bileşikler bitkide nematoda karşı sistemik dayanıklılığı uyarabilir. $\mathrm{Bu}$ şekilde farklı etki mekanizmasına sahip olan ve birbiri ile uyumlu olan türler ve izolatlar bir arada kullanılarak sinerjik bir etki meydana getirebilir (Sharon ve ark., 2011). Bu çalışmada kullanılan mikrobiyal gübreler arasında yer alan türlerden $T$. virens' in, in vitro'da $M$. incognita'ya karşı yumurta açılımını ve ikinci dönem larvanın hareketini engellediği tespit edilmesine rağmen, domates bitkisinde aynı nematoda karşı etkisiz olduğu belirlenmiştir (Meyer ve ark., 2000). Meyer ve ark (2000), izolatın in vitro koşullarda başarılı olmasına rağmen, bitkili ortamda etkisiz olarak tespit edilmesinin nedenini, izolatın domates köklerinde yeterince kolonize olamamasına, yeterli miktarda anatogistik madde üretememesine veya sera şartlarında nematodu baskılayıcı bileşiklerin oluşturulmamasına bağlamaktadır. Buna karşın, aynı izolatın biberde ise $M$. incognita'nın popülasyonunu azaltabildiği tespit edilmiştir (Meyer ve ark., 2001). Aynı fungus türünün farklı bir izolatını kullanan Herrera-Parra ve ark. (2017) ise $T$. virens'in, biberde aynı nematoda karşı etkisiz olduğunu belirlemiştir. Denemede kullanılan Rootsafer adlı mikrobiyal gübrenin içinde bulunan diğer türler $T$. harzianum ve $T$. lignorum'un kök-ur nematodu türlerinin popülasyonu azaltıcı etkiye sahip olduğunu gösteren çalışmalar da mevcuttur (Spiegel ve Chet, 1998; Sharon ve ark., 2001; Dababat ve ark., 2006; Sahebani ve Hadavi, 2008; Radwan ve ark., 2012; Al-Hazmi ve Javeed, 2016). Buna karşın, bu çalışmada kullanılan mikrobiyal gübreler içerisinde nematoda karşı en düşük etki, birden fazla Trichoderma türünü içeren Rootsafer uygulamasından tespit edilmiştir. Birden fazla mikroorganizmanın bir arada kullanılarak onların etkinliğinin artırılabileceği (sinerjik etki sağlanabileceği) ve bunun sonucu olarak bir veya daha fazla hedef organizmaya karş1, çevre şartlarına daha geniş toleranslı olarak kullanılabileceği düşünülebilir (Meyer ve ark. 2001). Fakat bu birlikteliklerin bazı sakıncaları da olabilir. Örneğin, antibiyosis ve rekabetten kaynaklanan antagonizm, mikroorganizmaların potansiyelini azaltabilir (Pierson ve Weller, 1994; Meyer ve ark., 2001). Çalışmamızda, mikrobiyal gübrelerin birlikte 2'li, 3'lü ve 4'lü kombinasyonlar şeklinde uygulamalarında, nematodun üreme indekisini azaltma bakımından tek uygulandıklarında göstermiş olduklarından daha az etki göstermeleri de bu hipotezi destekler niteliktedir. Sonuçlarımıza paralel olarak, Meyer ve ark. (2001) tarafindan biber'de M. incognita'ya karşı kombinasyonlar şeklinde yapılan uygulamaların, tekli uygulananlarla kıyaslandığında, daha az etkiler gösterdikleri tespit edilmiştir. Etkinliğin azalış nedeninin, mikroorganizmaların birbirine karşı antogonistik etki oluşturması ya da nematoda antogonistik etkiye sahip bileşiklerin üretiminin, kombinasyonlarda baskılanabileceği şeklinde yorumlanmıştır (Meyer ve ark., 2001).

Çalışmada kullanılan Nematofix'in, domates bitkisinde $M$. incognita'nın üremesini kontrole kıyasla \% 54 azaltması, mücadelede diğer yöntemlerle birlikte ümitvar olarak kullanılabileceğini göstermektedir. Ayrıca, mikrobiyal gübrelerin başarısını etkileyen en önemli faktörlerden biri de uygulama zamanıdır. Özellikle, nematod inokulasyonundan birkaç hafta önce yapılan mikrobiyal gübre uygulamalarıyla mücadelede başarı oranı artabilir (Silva ve ark., 2017). Bu nedenlerle, daha sonraki çalışmalarda nematodla doğal bulaşık topraklarda, biyolojik gübrelerin farklı uygulama zamanlarının etkilerinin ortaya konulması gerekmektedir.

\section{Teşekkür}

Çalışmada kullanılan ticari preparatları ücretsiz olarak temin eden Bioglobal AŞ. (Antalya, Türkiye) teşekkür ederiz.

\section{Kaynaklar}

Al-Hazmi, A.S., Javeed, M.T., 2016. Effects of different inoculum densities of Trichoderma harzianum and Trichoderma viride against 
Meloidogyne javanica on tomato. Saudi Journal of Biological Sciences, 23(2): 288-292.

Anonymous, 2018. FAOSTAT. (http://www.fao. org/faostat/en/\#data/QC) (Erişim tarihi: 28.02. 2018).

Aydınl1, G., Mennan, S., 2016. Identification of root-knot nematodes (Meloidogyne spp.) from greenhouses in the Middle Black Sea Region of Turkey. Turkish Journal of Zoology, 40(5): 675685.

Bridge, J., Page, S.L.J., 1980. Estimation of rootknot nematodes infestation levels using a rating chart. Tropical Pest Management, 26(3): 296298.

Burkett-Cadena, M., Kokalis-Burelle, N., Lawrence, K.S., Van Santen, E., Kloepper, J.W., 2008. Suppressiveness of root-knot nematodes mediated by rhizobacteria. Biological Control, 47(1): 55-59.

Cabanillas, E., Barker, K.R., Nelson, L.A., 1989. Growth of isolates of Paecilomyces lilacinus and their efficacy in biocontrol of Meloidogyne incognita on tomato. Journal of Nematology, 21(2): 164-172.

Cetintas, R., Kusek, M., Fateh, S.A., 2018. Effect of some plant growth-promoting rhizobacteria strains on root-knot nematode, Meloidogyne incognita, on tomatoes. Egyptian Journal of Biological Pest Control, 28: 7.

Cooper, K.M., Grandisons, G.S., 1986. Interaction of vesicular-arbuscular mycorrhizal fungi and root-knot nematode on cultivars of tomato and white clover susceptible to Meloidogyne hapla. Annals of Applied Biology, 108(3): 555-565.

Dababat, A.A., Sikora, R.A., Hauschild, R., 2006. Use of Trichoderma harzianum and Trichoderma viride for the biological control of Meloidogyne incognita on tomato. Communications in Agricultural and Applied Biological Sciences, 71(3): 953-961.

Dackman, C., Nordbring-Hertz, B., 1985. Fungal parasites of cereal cyst nematode, Heterodera avenae in southern Sweden. Journal of Nematology, 17(1): 50-55.

Djian-Caporalino, C., Molinari, S., Palloix, A., Ciancio, A., Fazari, A., Marteu, N., Ris, N., Castagnone-Sereno, P., 2011. The reproductive potential of the root-knot nematode Meloidogyne incognita is affected by selection for virulence against major resistance genes from tomato and pepper. European Journal of Plant Pathology, 131(3): 431-440.

Fernandes, R.H., Vieira, B.S., Fuga, C.A.G., Lopes, E.A., 2014. Pochonia chlamydosporia and Bacillus subtilis on the control of Meloidogyne incognita and $M$. javanica in tomato seedlings. Bioscience Journal, 30(1): 194-200.

Freire, F.C.O., Bridges, J., 1985. Parasitism of eggs, females and juveniles of Meloidogyne incognita by Paecilomyces lilacinus and Verticillium chlamydosporium. Fitopatologia Brasiliera, 10(3): 577-596.

Gaspard, J.T., Jaffee, B.A., Ferris, H., 1990. Association of Verticillium chlamydosporium and Paecilomyces lilacinus with root-knot nematode infested soil. Journal of Nematology, 22(2): 207-213.

Hariprasad, P., Venkateswaran, G., Niranjana, S.R., 2014. Diversity of cultivable rhizobacteria across tomato growing regions of Karnataka. Biological Control, 72: 9-16.

Herrera-Parra, E., Cristóbal-Alejo, J., RamosZapata, J.A., 2017. Trichoderma strains as growth promoters in Capsicum annuum and as biocontrol agents in Meloidogyne incognita. Agricultural Research, 77(4): 318-324.

Hussey, R.S., Barker, K.R., 1973. A comparison of methods of collecting inocula of Meloidogyne spp., including a new technique. Plant Disease Reporter, 57: 1025-1028.

Irving, F., Kerry, B.R., 1986. Variation between strains of the nematophagous fungus Verticillium chlamydosporium Goddard. II. Factors affecting parasitism of cyst nematode eggs. Nematologica, 32(4): 474-485.

Katı, T., Mennan, S., 2006. Kök-ur nematodları (Meloidogyne spp.) ile biyolojik mücadele. Ondokuz Mayıs Üniversitesi Ziraat Fakültesi Dergisi, 21(2): 265-274.

Kerry, B.R., Simon, A., Rovira, A.D., 1984. Observations on introduction of Verticillium chlamydosporium and other parasitic fungi into soil for the control of cereal cyst nematodes, Heterodera avenae. Annals of Applied Biology, 105(3): 509-516.

Liu, R., Dai, M., Wu, X., Li, M., Liu, X., 2012. Suppression of the root-knot nematode [Meloidogyne incognita (Kofoid \& White) Chitwood] on tomato by dual inoculation with arbuscular mycorrhizal fungi and plant growthpromoting rhizobacteria. Mycorrhiza, 22(4): 289-296.

Lopez-Perez, J.A., Strange, M.L., Kaloshian, I., Ploeg, A.T., 2006. Differential response of Mi gene-resistant tomato rootstocks to root-knot nematodes (Meloidogyne incognita). Crop Protection, 25(4): 382-388.

Lopez-Perez, J.A., Edwards, S., Ploeg, A., 2011. Control of root-knot nematodes on tomato in stone wool substrate with biological 
nematicides. Journal of Nematology, 43(2): 110-117.

Meyer, S.L.F., Massoud, S.I., Chitwood, D.J., Roberts, D.P., 2000. Evaluation of Trichoderma virens and Burkholderia cepacia for antagonistic activity against root-knot nematode, Meloidogyne incognita. Nematology, 2(8): 871879.

Meyer, S.L.F., Roberts, D.P., Chitwood, D.J., Carta, L.K., Lumsden, R.D., Mao, W., 2001. Application of Burkholderia cepacia and Trichoderma virens, alone and in combinations, against Meloidogyne incognita on bell pepper. Nematropica, 31(1): 75-86.

Pierson, E.A., Weller, D.M., 1994. Use of mixtures of fluorescent pseudomonads to suppress takeall and improve the growth of wheat. Phytopathology, 84(9): 940-947.

Radwan, M.A., Farrag, S.A.A., Abu-Elamayem, M.M., Ahmed, N.S., 2012. Biological control of the root-knot nematode, Meloidogyne incognita on tomato using bioproducts of microbial origin. Applied Soil Ecology, 56(1): 58-62.

Sahebani, N., Hadavi, N., 2008. Biological control of the root-knot nematode Meloidogyne javanica by Trichoderma harzianum. Soil Biology and Biochemistry, 40(8): 2016-2020.

Seid, A., Fininsa, C., Mekete, T., Decraemer, W., Wesemael, W.M., 2015. Tomato (Solanum lycopersicum) and root-knot nematodes (Meloidogyne spp.)-a century-old battle. Nematology, 17(9): 995-1009.

Serfoji, P., Rajeshkumar, S., Selvaraj, T., 2010. Management of root-knot nematode, Meloidogyne incognita on tomato cv Pusa Ruby. by using vermicompost, AM fungus, Glomus aggregatum and mycorrhiza helper bacterium, Bacillus coagulans. Journal of Agricultural Technology, 6(1): 37-45.

Sharon, E., Bar-Eyal, M., Chet, I., Herrera-Estrella, A., Kleifeld, O., Spiegel, Y., 2001. Biological control of the root-knot nematode Meloidogyne javanica by Trichoderma harzianum. Phytopathology, 91(7): 687-693.

Sharon, E., Chet, I., Spiegel, Y., 2011. Trichoderma as a biological control agent. In: K. Davies, Y. Spiegel (Eds.), Biological Control of PlantParasitic Nematodes: Building Coherence between Microbial Ecology And Molecular Mechanisms, Progress in Biological Control. Springer, Netherlands, pp. 183-201.
Shreenivasa, K.R., Krishnappa, K., Ravichandra, N.G., 2007. Interaction effects of arbuscular mycorrhizal fungus Glomus fasciculatum and root-knot nematode, Meloidogyne incognita on growth and phosphorous uptake of tomato. Karnataka Journal of Agricultural Sciences, 20(1): 57-61.

Siddiqui, Z.A., Mahmood, I., 1996. Biological control of plant parasitic nematodes by fungi: A review. Bioresource Technology, 58(3): 229239.

Siddiqui, I.A., Shaukat, S.S., 2003. Suppression of root-knot disease by Pseudomonas fluorescens CHA0 in tomato: importance of bacterial secondary metabolite, 2,4diacetylpholoroglucinol. Soil Biology and Biochemistry, 35(12): 1615-1623.

Siddiqui, Z.A., Akhtar, M.S., 2009. Effects of antagonistic fungi and plant growth-promoting rhizobacteria on growth of tomato and reproduction of the root-knot nematode, Meloidogyne incognita. Australasian Plant Pathology, 38(1): 22-28.

Silva, J.O., Santana, M.V., Freire, L.L., Ferreira, B.S., Rocha, M.R., 2017. Biocontrol agents in the management of Meloidogyne incognita in tomato. Ciência Rural, 47(10): e20161053.

Spiegel, Y., Chet, I., 1998. Evaluation of Trichoderma spp. as a biocontrol agent against soilborne fungi and plant-parasitic nematodes in Israel. Integrated Pest Management Reviews, 3(3): 169-175.

Terefe, M., Tefera, T., Sakhuja, P.K., 2009. Effect of a formulation of Bacillus firmus on root-knot nematode Meloidogyne incognita infestation and the growth of tomato plants in the greenhouse and nursery. Journal of Invertebrate Pathology, 100(2): 94-99.

Timper, P., 2014. Conserving and enhancing biological control of nematodes. Journal of Nematology, 46(2): 75-89.

Van Elsas, J.D., Jansson, J.K., Trevors, J.T., 2006. Modern Soil Microbiology. 2nd Edn. CRC Press, Thomson Publishing.

Van Loon, L.C., Bakker, P.A., Pieterse, C.M.J., 1998. Systemic resistance induced by rhizosphere bacteria. Annual Review of Phytopathology, 36(1): 453-483. 